\title{
AN APPLICATION OF AHP/ANP TO A WILDFIRE MANAGEMENT PROJECT TO HELP MITIGATE GLOBAL WARMING
}

\author{
Kazuya Kaku* \\ Satellite Applications and Promotion Center \\ Japan Aerospace Exploration Agency \\ Tokyo, Japan \\ E-mail: kaku.kazuya@jaxa.jp \\ Toshihisa Honma \\ Graduate School of Information Science and Technology \\ Hokkaido University \\ Sapporo, Japan \\ E-mail: honma@ist.hokudai.ac.jp \\ Masami Fukuda \\ International Arctic Research Center \\ University of Alaska Fairbanks \\ Fairbanks, AK, USA \\ E-mail:mfukuda@iarc.uaf.edu
}

\begin{abstract}
An application of the Analytic Hierarchy Process (AHP) and Analytic Network Process (ANP) technique to project management is studied. Project management has been formulated as a system of learning, whereas the AHP/ANP is not necessarily recognized as a standard methodology in the field of project management. In this study, we propose areas of project management that show great promise of the AHP/ANP application, along with a case study. As a case study, the ongoing "Sentinel Asia wildfire management support initiative" was chosen.
\end{abstract}

Keywords: AHP, ANP, project management, wildfire, Sentinel Asia, global warming, peat bog

\section{Introduction}

In various situations of project management, decision making is frequently required. For example, project portfolio management can be regarded as a problem of ranking the priorities of projects dependant on various criteria, where an evaluation by feelings based on experience, intuition, etc. as well as by quantitative facts is recognized to be important, which can be dealt with by the AHP/ANP technique.

In this study, we propose areas of project management that show great promise of the AHP/ANP application, along with a case study. As a case study, the ongoing "Sentinel Asia Wildfire Management Support Initiative" was chosen. The "Sentinel Asia" initiative was developed by the Asia-Pacific

${ }^{*}$ Corresponding author

Acknowledgements: This work was partially supported by Grant-in-Aid for Scientific Research (A) (20241042) from MEXT and JSPS. The authors wish to gratefully acknowledge all the members of Sentinel Asia project for their cooperation in promoting the project. 
Regional Space Agency Forum (APRSAF) in 2006 to apply space technology to the disaster management in the Asia-Pacific region. Under Sentinel Asia, a dedicated Wildfire Working Group has been established to apply remote sensing technology to the management of wildfire. Wildfire is one of the major and most chronic phenomena affecting many countries in the region, having a serious impact on property and human health. Furthermore, effects of wildfires are of great relevance at a global level, and accordingly bear substantial influence on global warming.

The objectives of this study are as follows:

- To overview a series of project management activities and show areas to which the AHP/ANP technique is useful.

- To show usefulness of the AHP/ANP technique by giving an example of its application to a project management of an ongoing project.

\section{Application of AHP/ANP to project management}

\subsection{Project management system}

Project management is systematized as the PMBOK (Project Management Book of Knowledge) by the PMI (Project Management Institute). It consists of nine knowledge areas: Integration Management, Scope Management, Time Management, Cost Management, Quality Management, Human Resources Management, Communications Management, Risk Management, and Procure Management. Portfolio management deals with a group of projects and manages them totally.

\subsection{Decision-making in project management}

In various situations of project management, decision-makings based on the ranking of priorities are required. For decision makings, proper evaluation for properly identified components is essential. Furthermore, for proper evaluation, proper methodology is required, which should be fair and universally accepted, and therefore, be mathematically reasonable. On the other hand, an evaluation by feelings based on experience, intuition, etc. as well as by quantitative facts is recognized to be important. A framework which incorporates both human senses and mathematical approach is needed.

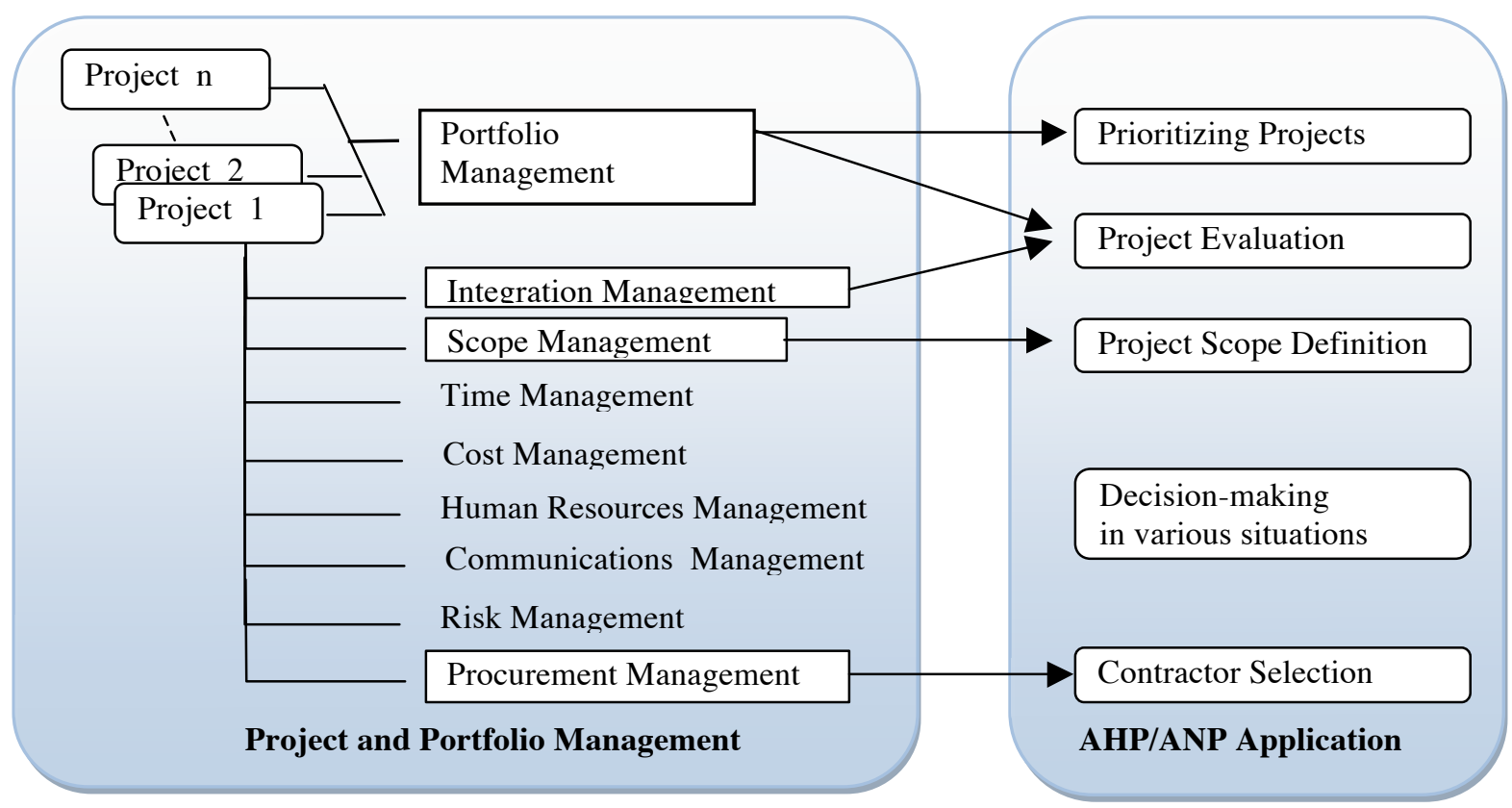

Figure 1. AHP/ANP application in the field of project management 
In the field of project management, a check-list method has been conventionally used for evaluating and ranking of priorities. The check-list method is used to set-out the items to be evaluated and allot proper marks to each item for evaluation. The point at issue is that the method leaves room for arbitrariness in the allotment of marks.

\subsection{Application of AHP/ANP to project management}

In Figure 1, major areas and subjects in the field of project management to which the AHP/ANP can be applied are shown.

From the viewpoint of project management, the AHP/ANP has the following characteristics:

- AHP can mathematically deal with an evaluation based on human feelings which include experience, intuition, etc.

- AHP recognizes a subject as a 3-step-hierarchical structure such as "Goal", "Criteria", and "Alternative". This process provides an opportunity to see the subject in a comprehensive, manifold, and interdisciplinary way.

- AHP is also useful for fostering agreement by applying it as a decision-making tool.

\section{Case study}

As a case study, the ANP was applied to a scope definition problem of ongoing project, Sentinel Asia wild fire management initiative.

\subsection{Sentinel Asia}

According to statistics (by ADRC-Natural Disasters Data Book-2006), the Asia region has been seriously damaged by natural disasters over the last 30 years. This is compounded by its high levels of population (close to 3 billion). Disasters occurring in Asia comprise 37 percent of the worldwide total. The region has 57 percent of global fatalities and 89 percent of the total victims associated with such disasters.

In view of these circumstances, APRSAF proposed Sentinel Asia in 2005 to showcase the value and impact of Earth observation technologies, combined with near-real-time internet dissemination methods and Web-GIS mapping tools for disaster management support in the Asia-Pacific region. APRSAF was established in 1993 in response to the declaration adopted by the Asia-Pacific International Space Year Conference (APIC) in 1992, to enhance the development of each country's space programme and to exchange views on future cooperation in space activities in the Asia-Pacific region. It was originally designed to provide opportunities for regional space agencies and associated governmental bodies to exchange technical views, opinions, and information on national space programmes and space resources.

The Sentinel Asia (SA) initiative is a collaboration between space agencies and disaster management agencies, applying remote sensing and Web-GIS technologies to assist disaster management in the AsiaPacific region. It aims to:

- Improve safety in society by ICT and space technology.

- Improve speed and accuracy of disaster preparedness and early warning.

- Minimize the number of victims and social/economic losses.

SA is a voluntary initiative led by APRSAF. Its goal is to share disaster information in near-real-time across the Asia-Pacific region, using Web-GIS platform. Its architecture is designed to operate initially as an internet-based, node-distributed information distribution backbone, eventually distributing relevant satellite and in situ spatial information on multiple hazards in the Asia-Pacific region.

A step-by-step approach for implementation of this dissemination system was adopted as follows:

- Step1: Implementation of the backbone Sentinel Asia data dissemination system as a pilot project, to showcase the value and impact of the technology using standard internet dissemination systems (2006-2007). (Kaku et al., 2006) 
- Step2: Expansion of the dissemination backbone with new satellite communication systems, and enhancement of activities based on experiences in Step1 and new requirements (2008-2012). (Kaku, 2008c)

- Step3: Establishment of a comprehensive disaster management support system (2013 onwards).

SA Step1 has achieved its overall goals. The Sentinel Asia website (Figure 2) has operated since October, 2006. It has served as a good demonstrator project to share disaster-related information obtained by several Earth observation satellites such as Advanced Land Observing Satellite (ALOS), Indian Remote Sensing Satellites (IRS), Multi-functional Transport Satellite 1R (MTSAT-1R), Terra, and Aqua. It has also demonstrated recent advances in web-mapping technologies and ICT systems.

\section{Sentinel Asia Web Site: \\ http://dmss.tksc.jaxa.jp/sentinel/}

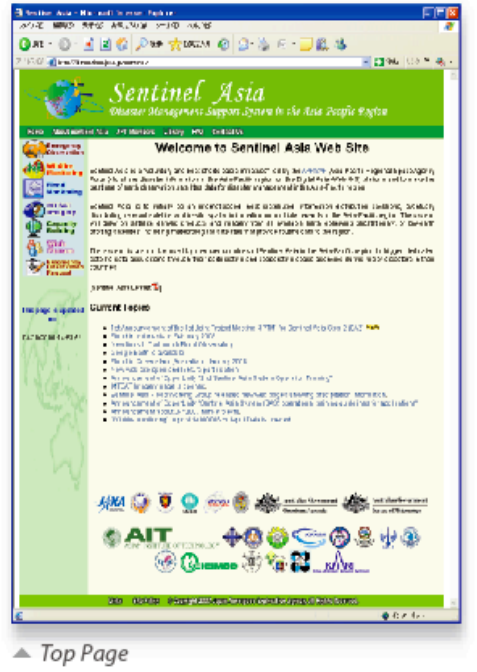

Figure 2. Sentinel Asia website (URL: http://dmss.tksc.jaxa.jp/sentinel/)

SA is promoted with cooperation amongst the space community (APRSAF), the international community (UN ESCAP, UN OOSA, ASEAN, Asian Institute of Technology (AIT) etc.), and the disaster reduction community (Asian Disaster Reduction Center (ADRC) and its member countries). To support the implementation of the SA project, a Joint Project Team (JPT) was organized. Membership in the JPT is open to all the APRSAF member countries, disaster prevention organizations, and regional/international organizations that are prepared to contribute their experiences and technical capabilities and wish to participate in technical aspects of disaster information sharing activities. JPT consists of 51 organizations from 20 countries and eight international organizations at the time of writing. The Japan Aerospace Exploration Agency (JAXA) is a secretariat of the JPT.

The main activities of SA are as follows:

- Emergency observation in case of major disasters by Earth observation satellites via observation requests of JPT and ADRC members.

- Wildfire monitoring and flood monitoring.

- Capacity building to develop human resources and a human network to utilize the information provided by the website. 


\subsection{Sentinel Asia wildfire management support initiative}

Wildfire is one of the major and recurring phenomena (Figure 3), which has a serious impact on lives and properties, affecting many countries in the region. In comparison to other disasters in the region, it may not cause many fatalities, but it causes serious damages to health due to smoke. Furthermore, its effects are of high importance both at a regional and global level, and accordingly exert substantial influence on global warming. For example, IPCC's forth edition of scientific report on global warming in 2007 had clearly pointed out that a huge amount of carbon dioxide has been emitted from the wild fire. They also noted the importance for reducing the wild fire occurrences. Responding to the concerns from Asian countries, wildfire monitoring was chosen as one of the Sentinel Asia's core activities. Having accurate information on the location and intensity of the fires, and subsequent control of wildfires, are therefore very important and urgent tasks across the region.

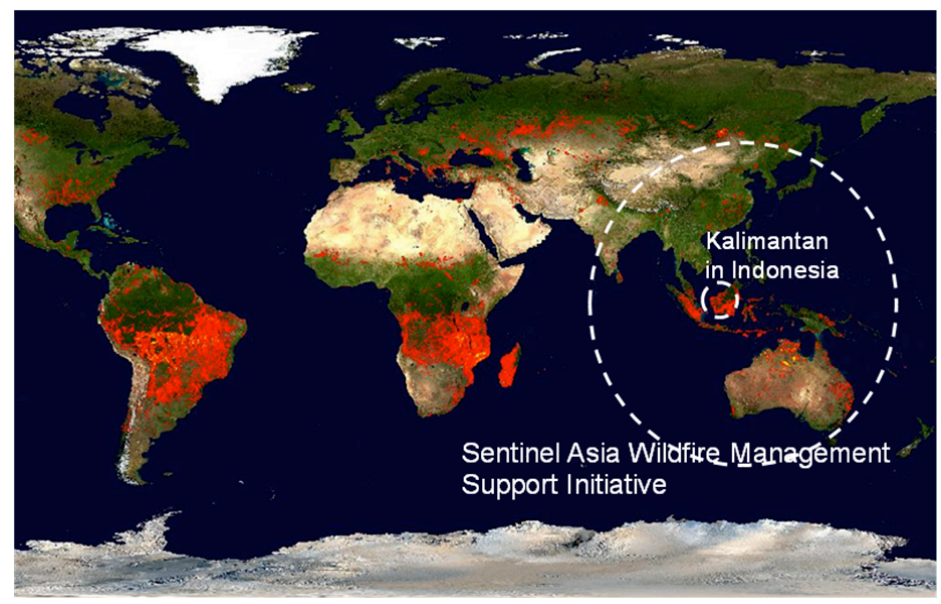

Figure 3. World fire map detected by satellites (NASA MODIS onboard Aqua and Terra) in October 2007 (from NASA website)

The Wildfire Working Group (WG) has been organized under international cooperation with WG members of Hokkaido University, the University of Tokyo, the National University of Singapore, the Asian Institute of Technology (AIT), the Commonwealth Scientific and Industrial Research Organisation (CSIRO) in Australia, the National Institute of Aeronautics and Space (LAPAN) in Indonesia, and JAXA, among others. Prof. M. Fukuda of the University of Alaska Fairbanks was selected as the WG leader. The project is operated under international cooperation in the framework of Sentinel Asia based on the experience and knowledge of similar activities such as for boreal forest/tundra fire in the Siberia/Alaska and for bush/shrub/grass fire in Australia (Held et al., 2003).

The main activities of Sentinel Asia wildfire management are as follows:

- To implement a near-real-time "wildfire observing system" covering the Asia-Pacific region, using the agreed-on node-distributed Sentinel Asia backbone and Web-GIS visualization system. AIT, the University of Tokyo, CSIRO, and the Center for Remote Imaging, Sensing and Processing (CRISP) are providing hotspot information.

- To coordinate activities such as validation of fire detection across the region in order to improve the hotspots detection algorithm. Six kinds of algorithms developed by Hokkaido University, CRISP, Soul National University, and JAXA are under study, including AIT (MOD14 version4) and the University of Tokyo (MOD14 version5). These algorithms are featured in "Asian Journal of GEOINFORMATICS, vol. 8, no. 3" in detail. (Kaku et al., 2008a)

- Risk analysis for detected hotspots. 
- Fire expansion forecasting and smoke forecasting applying real-time Volcano Plume Tracking (PUFF Model) are planned for detected hotspots, and critical hotspots will be distinguished for early fire control by firefighters. This scheme is a goal of the Sentinel Asia wildfire management initiative, which is shown in Figure 4.

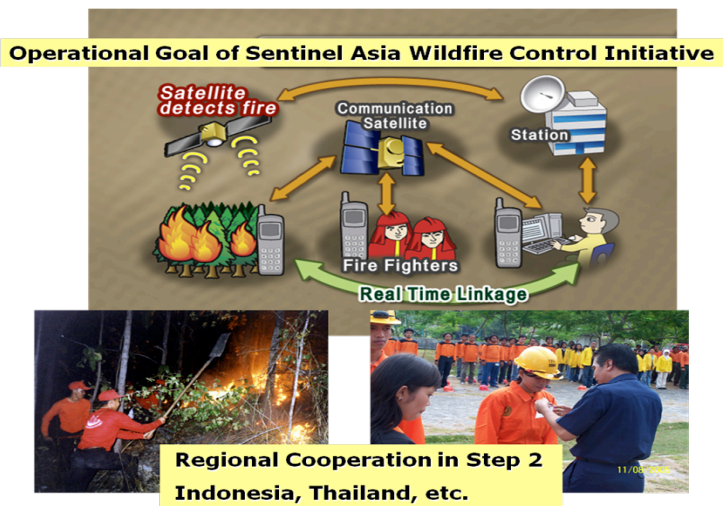

Figure 4. Operational goal of the Sentinel Asia wildfire management initiative (left-hand side photo: courtesy of National Park, Wildlife and Plant Conservation Department, Thailand)

\subsection{Subject}

The purpose is to determine a scope of a new project for Kalimantan in Indonesia (Figure 5), expanding Sentinel Asia wildfire management support initiative which is originally initiated in order to contribute to disaster management in the Asia-Pacific region. The goal of the new project is to control emission of carbon dioxide $\left(\mathrm{CO}_{2}\right)$ from wild-land for the purpose of mitigation of global warming.

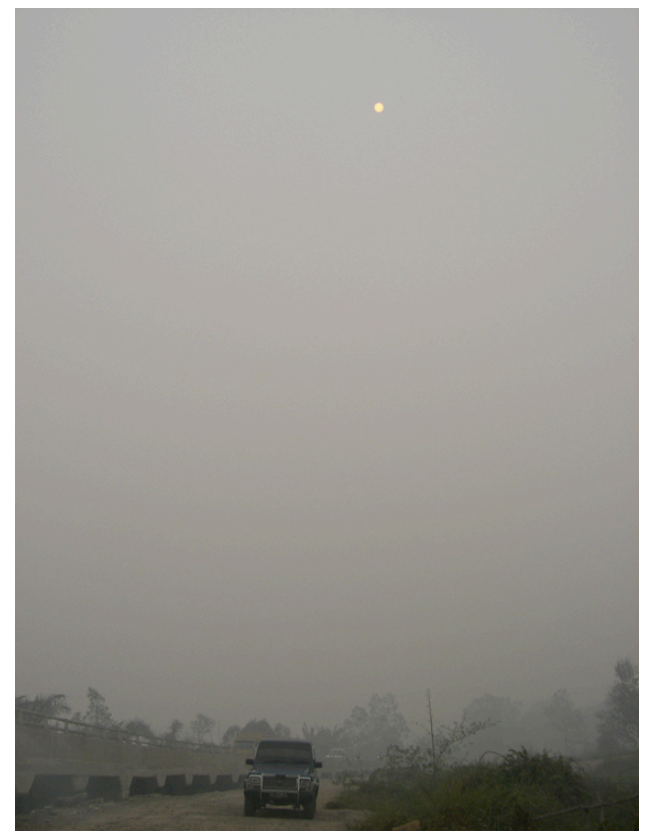

Figure 5. Haze caused by peat bog fire in Kalimantan, Indonesia in October 2006

(photo: courtesy of H. Hayasaka, Hokkaido University, Japan) 


\subsection{Analysis of the subject}

This area (Kalimantan) is characterized by being covered by a peat bog, which has the following characteristics from the viewpoint of carbon dioxide $\left(\mathrm{CO}_{2}\right)$ cycle:

- Peat bog shows significant characteristics from the viewpoint of carbon dioxide $\left(\mathrm{CO}_{2}\right)$ cycle. The peat bog emits $\mathrm{CO}_{2}$ not only from the peat fires but also due to activities of microbes as they become dry.

- A large proportion of the fires are caused by humans, most of which are due to slash-and-burnfarming.

- This region is affected by wildfires and their associated smoke in the dry season and floods in the rainy season every year. Floods wash away the fertile soil obtained by slash-and-burning. This is why slash-and-burning is required every year for farming. Irrigation of the peat bog and slashand-burn farming method are essential for farming.

- It is reported that the gross volume of $\mathrm{CO}_{2}$ emitted by the peat bog in Indonesia is more than the total gross volume of $\mathrm{CO}_{2}$ emitted in Japan (Page et al, 2002).

The wildfire management chronologic cycle is studied and shown in Figure 6, in which main activities related to wildfire and forest (including a peat bog) management are included: "political measures such as a ban on slash-and-burn-farming and indemnity payment for it", "enlightenment and capacity building to develop human resources at the country", "forest (including peat bog) management and conservation", "early fire detection and control", and "burn assessment and afforestation".

Political measures such as a ban on slash-and-burn-farming shows a quick effect for reduction of $\mathrm{CO}_{2}$ emission, but it will be difficult to last. Peat bog management is essential to $\mathrm{CO}_{2}$ management because peat bog emits $\mathrm{CO}_{2}$ as they become dry. Early fire detection and control are main activities of Sentinel Asia wildfire management support initiative, and are also essential to $\mathrm{CO}_{2}$ management because peat bog fires emit a large quantity of $\mathrm{CO}_{2}$. Afforestation after burn assessment is also important for $\mathrm{CO}_{2}$ management, but it takes time.

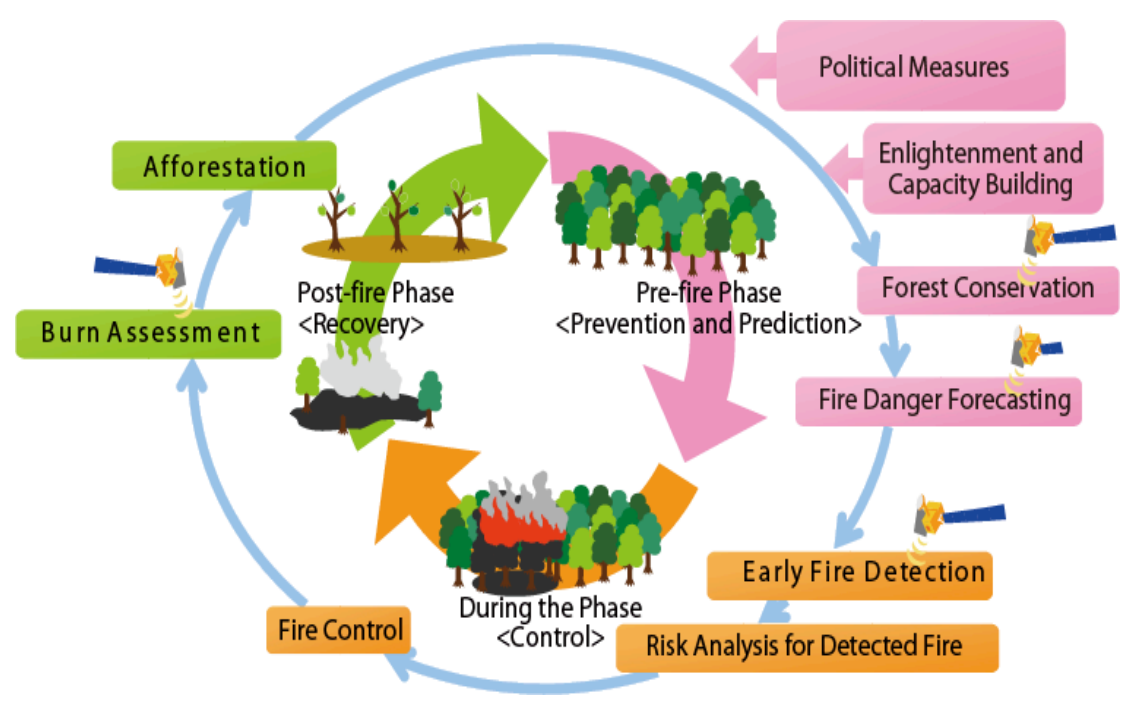

Figure 6. Forest and wildfire management cycle 


\subsection{ANP analysis}

Structuring hierarchy (Kinoshita, 2000)

Based on the analysis of the subject, a hierarchy is structured as shown in Figure 7, where the ANP feedback system is applied. With a view to determine the scope of the project by prioritizing activities such as "political measures" (A1), "enlightenment and capacity building" (A2), "forest (including peat bog) management and conservation" (A3), "early fire detection and control" (A4), and "burn assessment and afforestation" (A5), two scenarios, "contribution to mitigation of global warming" (S1) and "contribution to disaster management (Sentinel Asia)" (S2), are set-out. Concerning criteria, " $\mathrm{CO}_{2}$ reduction" (C1), "application of remote sensing technology" (C2), and "quick effect (within about 5 years)" (C3) are adopted. An inner-dependence among alternatives, shown in Figure 8, is introduced. The analysis by applying the ANP series system to this subject is already reported (Kaku et al., 2008b).

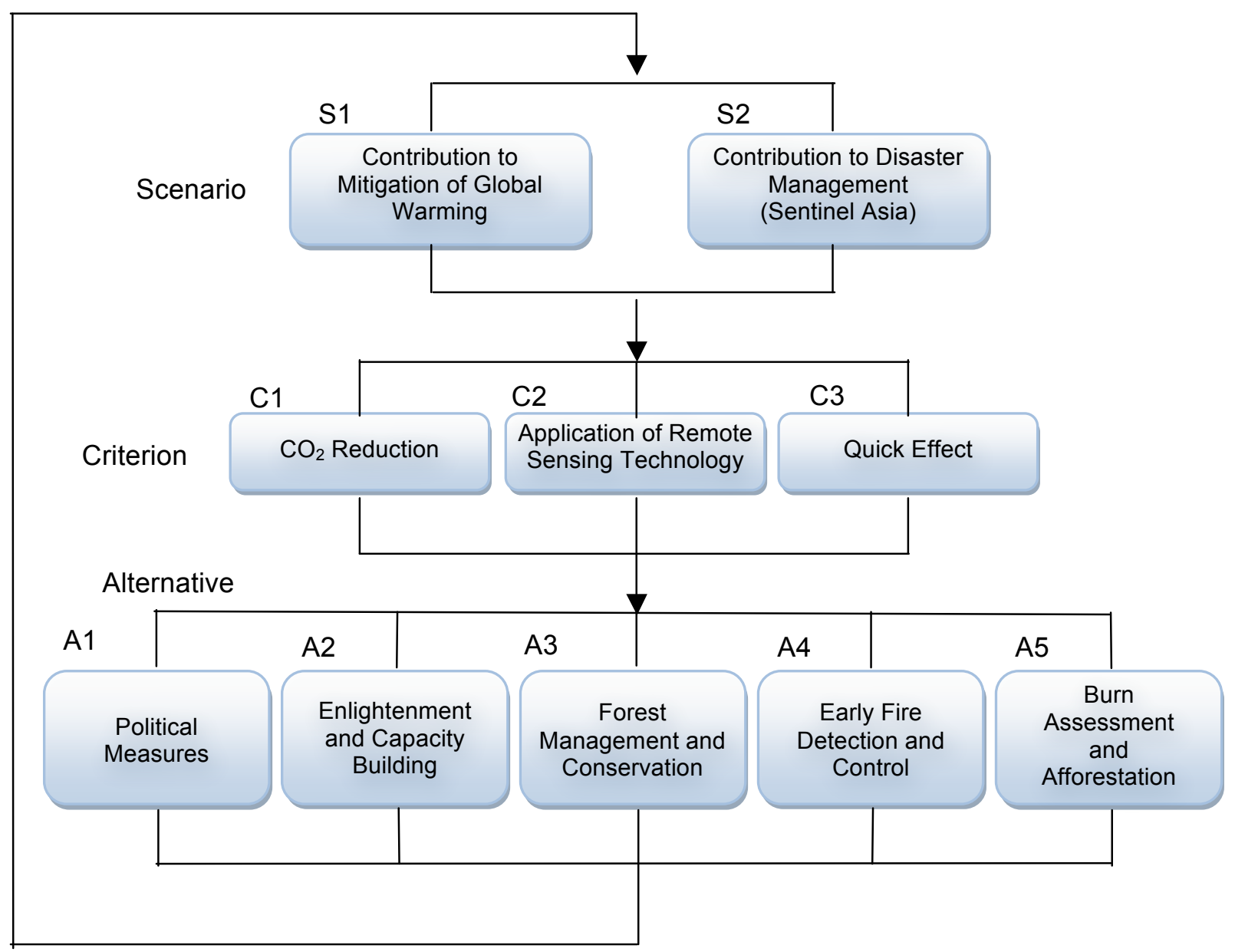

Figure 7. Hierarchical structure of ANP feedback system

Calculation of weights (Kinoshita, 2000)

The ANP analysis is performed by paired comparison and solving subsequent eigenvalue problem to obtain a weight of each element. Paired comparisons of scenarios from the viewpoint of each alternative are shown in Table 1, and weights of scenarios with respect to each alternative are obtained as follows: 


$$
W_{S}={ }_{S 2}\left(\begin{array}{ccccc}
A 1 & A 2 & A 3 & A 4 & A 5 \\
0.75 & 0.5 & 0.75 & 0.25 & 0.833 \\
0.25 & 0.5 & 0.25 & 0.75 & 0.167
\end{array}\right)
$$

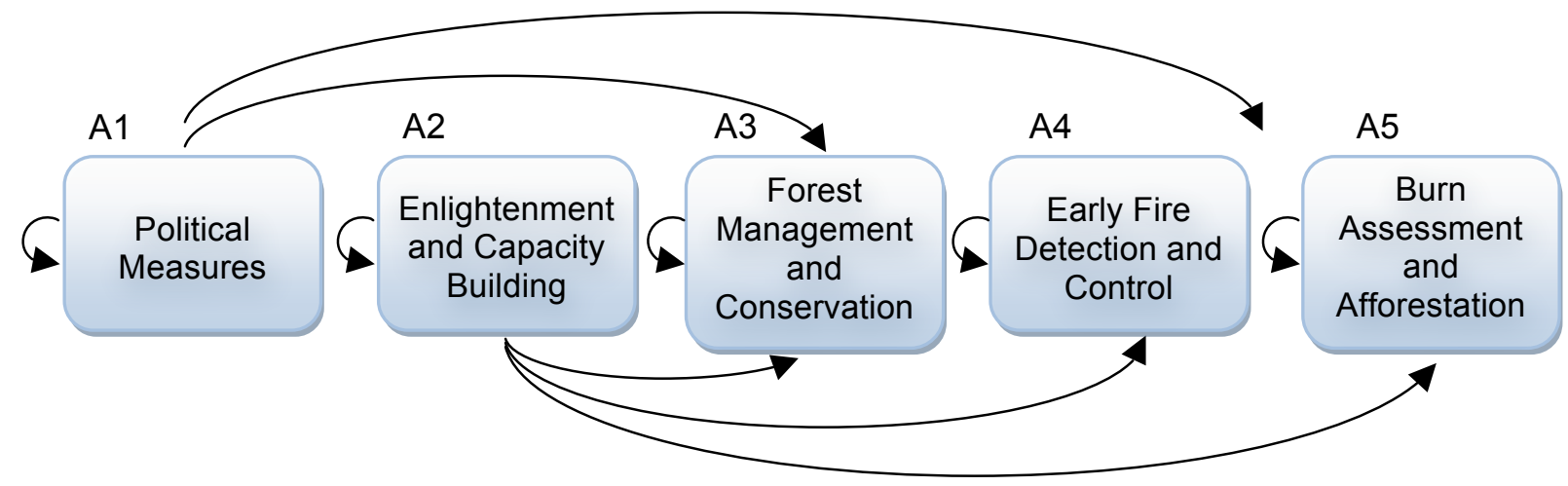

Figure 8. Inner-dependence among alternatives

Paired comparisons of criteria from the viewpoint of each scenario are shown in Table 2, and weights of criteria with respect to each scenario are obtained as follows:

$$
W_{C}=\begin{gathered}
C 1 \\
C 2 \\
C 3
\end{gathered}\left(\begin{array}{cc}
0.714 & 0.105 \\
0.143 & 0.637 \\
0.143 & 0.258
\end{array}\right)
$$

Table 1. Paired comparison of scenario w.r.t . alternative

\begin{tabular}{|l|l|l|l|}
\hline A1 & S1 & S2 & weight \\
\hline S1 & 1 & 3 & 0.75 \\
\hline S2 & $1 / 3$ & 1 & 0.25 \\
\hline
\end{tabular}

Consistency Index $(\mathrm{CI})=0.0$

\begin{tabular}{|l|l|l|l|}
\hline A4 & S1 & S2 & weight \\
\hline S1 & 1 & 3 & 0.25 \\
\hline S2 & $1 / 3$ & 1 & 0.75 \\
\hline \multicolumn{4}{|c}{ CI $=0.0$}
\end{tabular}

\begin{tabular}{|l|l|l|l|}
\hline A2 & S1 & S2 & weight \\
\hline S1 & 1 & 1 & 0.5 \\
\hline S2 & 1 & 1 & 0.5 \\
\hline \multicolumn{4}{|c|}{ CI $=0.0$} \\
\hline
\end{tabular}

\begin{tabular}{|l|l|l|l|}
\hline A5 & S1 & S2 & weight \\
\hline S1 & 1 & 5 & 0.833 \\
\hline S2 & $1 / 5$ & 1 & 0.167 \\
\hline \multicolumn{4}{|c}{ CI $=0.0$}
\end{tabular}

\begin{tabular}{|l|l|l|l|}
\hline A3 & S1 & S2 & weight \\
\hline S1 & 1 & 3 & 0.75 \\
\hline S2 & $1 / 3$ & 1 & 0.25 \\
\hline \multicolumn{4}{|c}{ CI $=0.0$}
\end{tabular}

Measure of paired comparison

\begin{tabular}{|l|l|}
\hline Value & Definition \\
\hline 1 & equal importance \\
\hline 3 & weak importance \\
\hline 5 & strong importance \\
\hline 7 & very strong importance \\
\hline 9 & absolute importance \\
\hline
\end{tabular}

Table 2. Paired comparison of criterion w.r.t . scenario.

\begin{tabular}{|l|l|l|l|l|}
\hline S1 & C1 & C2 & C3 & weight \\
\hline C1 & 1 & 5 & 5 & 0.714 \\
\hline
\end{tabular}

\begin{tabular}{|l|l|l|l|l|}
\hline $\mathrm{C} 2$ & $1 / 5$ & 1 & 1 & 0.143 \\
\hline $\mathrm{C} 3$ & $1 / 5$ & 1 & 1 & 0.143 \\
\hline \multicolumn{5}{|c}{$\mathrm{CI}=0.0$}
\end{tabular}




\begin{tabular}{|l|l|l|l|l|}
\hline S2 & C1 & C2 & C3 & weight \\
\hline C1 & 1 & $1 / 5$ & $1 / 3$ & 0.105 \\
\hline C2 & 5 & 1 & 3 & 0.637 \\
\hline C3 & 3 & $1 / 3$ & 1 & 0.258 \\
\hline \multicolumn{4}{|c}{ CI $=0.019$}
\end{tabular}

Table 3. Paired comparison of alternative w.r.t . criterion.

\begin{tabular}{|l|l|l|l|l|l|l|}
\hline C1 & A1 & A2 & A3 & A4 & A5 & weight \\
\hline A1 & 1 & 1 & $1 / 3$ & $1 / 3$ & 1 & 0.111 \\
\hline A2 & 1 & 1 & $1 / 3$ & $1 / 3$ & 1 & 0.111 \\
\hline A3 & 3 & 3 & 1 & 1 & 3 & 0.333 \\
\hline A4 & 3 & 3 & 1 & 1 & 3 & 0.333 \\
\hline A5 & 1 & 1 & $1 / 3$ & $1 / 3$ & 1 & 0.111 \\
\hline
\end{tabular}

\begin{tabular}{|l|l|l|l|l|l|l|}
\hline C2 & A1 & A2 & A3 & A4 & A5 & weight \\
\hline A1 & 1 & 1 & $1 / 5$ & $1 / 7$ & $1 / 3$ & 0.053 \\
\hline A2 & 1 & 1 & $1 / 5$ & $1 / 7$ & $1 / 3$ & 0.053 \\
\hline A3 & 5 & 5 & 1 & $1 / 3$ & 3 & 0.258 \\
\hline A4 & 7 & 7 & 3 & 1 & 5 & 0.514 \\
\hline A5 & 3 & 3 & $1 / 3$ & $1 / 5$ & 1 & 0.122 \\
\hline
\end{tabular}

\begin{tabular}{|l|l|l|l|l|l|l|}
\hline C3 & A1 & A2 & A3 & A4 & A5 & weight \\
\hline A1 & 1 & 5 & 3 & 3 & 5 & 0.466 \\
\hline A2 & $1 / 5$ & 1 & $1 / 3$ & $1 / 3$ & 1 & 0.073 \\
\hline A3 & $1 / 3$ & 3 & 1 & 1 & 3 & 0.194 \\
\hline A4 & $1 / 3$ & 3 & 1 & 1 & 3 & 0.194 \\
\hline A5 & $1 / 5$ & 1 & $1 / 3$ & $1 / 3$ & 1 & 0.073 \\
\hline \multicolumn{4}{|c|}{ CI $=0.014$} \\
\hline
\end{tabular}

Table 4. Paired comparison of inner dependence among alternatives

Influence on A3 w.r.t. C1

\begin{tabular}{|l|l|l|l|l|}
\hline & A1 & A2 & A3 & weight \\
\hline A1 & 1 & 2 & $1 / 5$ & 0.167 \\
\hline A2 & $1 / 2$ & 1 & $1 / 7$ & 0.094 \\
\hline A3 & 5 & 7 & 1 & 0.740 \\
\hline \multicolumn{4}{|c}{ CI $=0.07$}
\end{tabular}

Influence on A4 w.r.t. C1

\begin{tabular}{|l|l|l|l|}
\hline & A2 & A4 & weight \\
\hline A2 & 1 & $1 / 7$ & 0.125 \\
\hline A4 & 7 & 1 & 0.875 \\
\hline \multicolumn{4}{|c}{ CI $=0.0$}
\end{tabular}

Influence on A5 w.r.t. C1

\begin{tabular}{|l|l|l|l|l|}
\hline & A1 & A2 & A5 & weight \\
\hline A1 & 1 & 1 & $1 / 5$ & 0.143 \\
\hline A2 & 1 & 1 & $1 / 5$ & 0.143 \\
\hline A5 & 5 & 5 & 1 & 0.714 \\
\hline
\end{tabular}

Influence on A3 w.r.t. C2

\begin{tabular}{|l|l|l|l|l|}
\hline & A1 & A2 & A3 & weight \\
\hline A1 & 1 & 1 & $1 / 7$ & 0.111 \\
\hline A2 & 1 & 1 & $1 / 7$ & 0.111 \\
\hline A3 & 7 & 7 & 1 & 0.778 \\
\hline
\end{tabular}

Influence on A4 w.r.t. C2

\begin{tabular}{|l|l|l|l|}
\hline & A2 & A4 & weight \\
\hline A2 & 1 & $1 / 7$ & 0.125 \\
\hline A4 & 7 & 1 & 0.875 \\
\hline \multicolumn{4}{|c}{ CI $=0.0$}
\end{tabular}

Influence on A5 w.r.t. C2

\begin{tabular}{|l|l|l|l|l|}
\hline & A1 & A2 & A5 & weight \\
\hline A1 & 1 & 1 & $1 / 9$ & 0.091 \\
\hline A2 & 1 & 1 & $1 / 9$ & 0.091 \\
\hline A5 & 9 & 9 & 1 & 0.818 \\
\hline
\end{tabular}

Influence on A3 w.r.t. C3

\begin{tabular}{|l|l|l|l|l|}
\hline & A1 & A2 & A3 & weight \\
\hline A1 & 1 & 3 & $1 / 2$ & 0.292 \\
\hline A2 & $1 / 3$ & 1 & $1 / 7$ & 0.093 \\
\hline A3 & 2 & 7 & 1 & 0.615 \\
\hline \multicolumn{4}{|c}{ CI $=0.01$}
\end{tabular}

Influence on A4 w.r.t. C3

\begin{tabular}{|l|l|l|l|}
\hline & A2 & A4 & weight \\
\hline A2 & 1 & $1 / 5$ & 0.167 \\
\hline A4 & 5 & 1 & 0.833 \\
\hline
\end{tabular}

Influence on A5 w.r.t. C3 


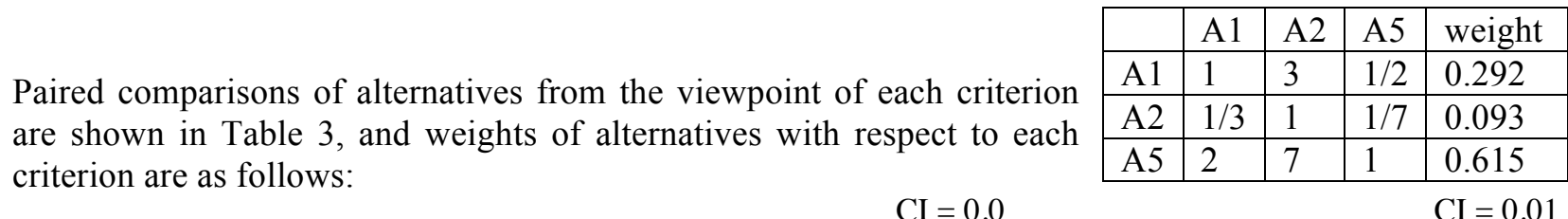

$$
\begin{aligned}
& \begin{array}{lll}
C 1 & C 2 & C 3
\end{array}
\end{aligned}
$$

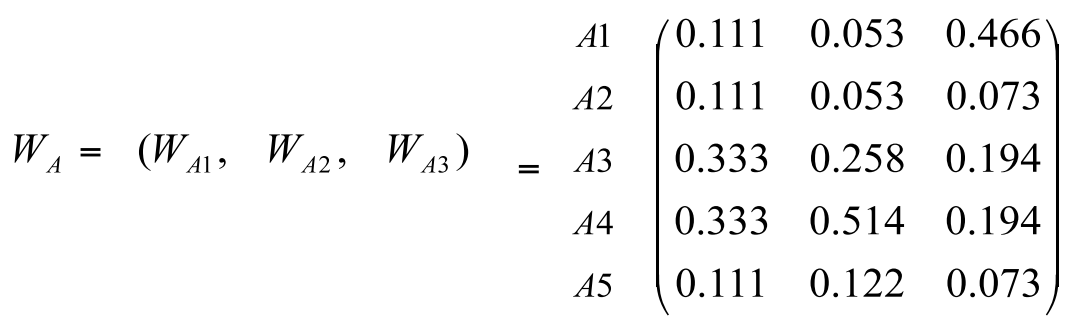

Concerning a inner dependence among alternatives shown in Figure 7, paired comparisons are shown in Table 4, and weights are calculated as follows:

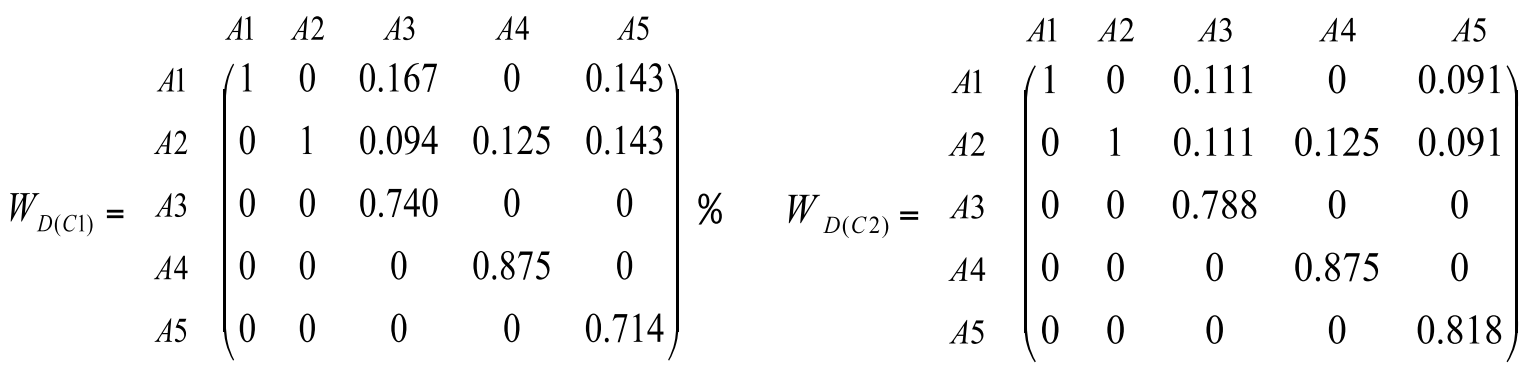

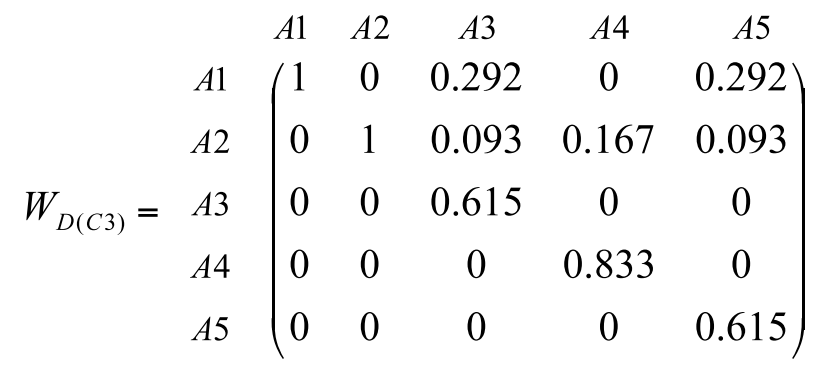

$$
\begin{aligned}
& \widetilde{W}_{A}=\left(W_{D(C 1)} \# W_{A 1}, \quad W_{D(C 2)} \# W_{A 2}, W_{D(C 3)} \# W_{A 3}\right) \\
& \begin{array}{lll}
C 1 & C 2 & C 3
\end{array} \\
& \begin{array}{l}
A 1 \\
A 2 \\
A 3 \\
A 4 \\
A 5
\end{array}\left(\begin{array}{lll}
0.182 & 0.093 & 0.544 \\
0.200 & 0.157 & 0.130 \\
0.246 & 0.201 & 0.119 \\
0.079 & 0.450 & 0.162 \\
0.100 & 0.045
\end{array}\right)
\end{aligned}
$$


Finally, a super matrix $W$ is defined as follows:

$$
\begin{aligned}
& W=\begin{array}{c}
\text { Scinario } \\
\text { Crinario } \\
\text { Criterion } \\
\text { Alternative }
\end{array}\left(\begin{array}{ccc}
0 & 0 & W_{S} \\
W_{C} & 0 & 0 \\
0 & \widetilde{W}_{A} & 0
\end{array}\right)
\end{aligned}
$$

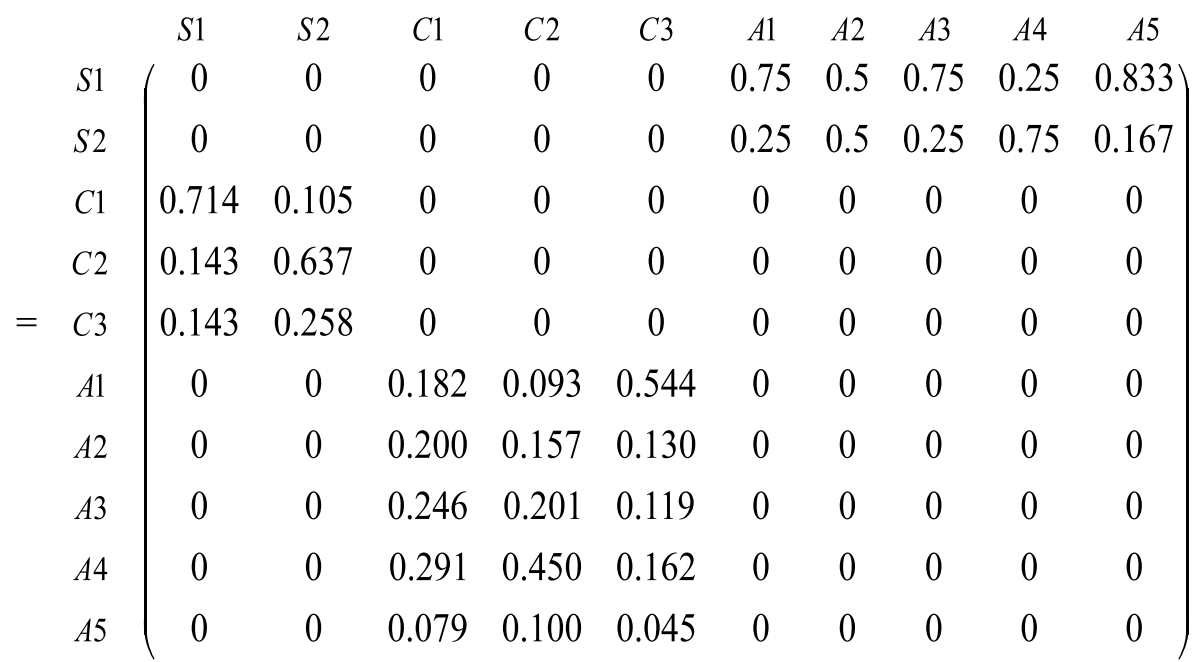

Then, $W^{3 \mathrm{n}+1}$ is calculated as follows:

$$
W^{3 n+1}=\left(\begin{array}{ccc}
0 & 0 & \left(W_{S} \widetilde{W}_{A} W_{C}\right)^{n} W_{S} \\
\left(W_{C} W_{S} \widetilde{W}_{A}\right)^{n} W_{C} & 0 & 0 \\
0 & \left(\widetilde{W}_{A} W_{C} W_{S}\right)^{n} \widetilde{W}_{A} & 0
\end{array}\right)
$$

where $W^{3 n+1}$ means the weight of the ANP feedback system when a cycle is repeated $(3 n+1)$ times.

Since the super matrix $W$ is a stochastic matrix, the limit of $W^{3 \mathrm{n}+1}$ converges to a matrix $W^{*}$ with identical columns as follows (Saaty, 1980):

$$
\begin{aligned}
W^{*} & =\lim _{n \rightarrow \infty} W^{3 n+1} \\
& =\left(\begin{array}{ccc}
0 & 0 & W_{S}^{*} \\
W_{C}^{*} & 0 & 0 \\
0 & W_{A}^{*} & 0
\end{array}\right)
\end{aligned}
$$

where

$$
W_{S}^{*}=\lim _{n \rightarrow \infty}\left(W_{S} \widetilde{W}_{A} W_{C}\right)^{n} W_{S}
$$




$$
\begin{aligned}
W_{C}^{*} & =\lim _{n \rightarrow \infty}\left(W_{C} W_{S} \widetilde{W}_{A}\right)^{n} W_{C} \\
W_{A}^{*} & =\lim _{n \rightarrow \infty}\left(\widetilde{W}_{A} W_{C} W_{S}\right)^{n} \widetilde{W}_{A}
\end{aligned}
$$

After calculations, finally we get following results:

$$
\begin{array}{ccccccccccccc} 
& S 1 & S 2 & C 1 & C 2 & C 3 & A 1 & A 2 & A 3 & A 4 & A 5 & \text { weight } \\
S 1 & 0 & 0 & 0 & 0 & 0 & 0.55 & 0.55 & 0.55 & 0.55 & 0.55 & 0.55 \\
C 2 & 0 & 0 & 0 & 0 & 0 & 0.45 & 0.45 & 0.45 & 0.45 & 0.45 & 0.45 \\
C 1 & 0.44 & 0.44 & 0 & 0 & 0 & 0 & 0 & 0 & 0 & 0 & 0.44 \\
C 2 & 0.36 & 0.36 & 0 & 0 & 0 & 0 & 0 & 0 & 0 & 0 & 0.36 \\
W^{*}= & 03 & 0.20 & 0.20 & 0 & 0 & 0 & 0 & 0 & 0 & 0 & 0 & 0.20 \\
A 1 & 0 & 0 & 0.32 & 0.32 & 0.32 & 0 & 0 & 0 & 0 & 0 & 0.32 \\
A 2 & 0 & 0 & 0.17 & 0.17 & 0.17 & 0 & 0 & 0 & 0 & 0 & 0.17 \\
A 3 & 0 & 0 & 0.21 & 0.21 & 0.21 & 0 & 0 & 0 & 0 & 0 & 0.21 \\
A 4 & 0 & 0 & 0.33 & 0.33 & 0.33 & 0 & 0 & 0 & 0 & 0 & 0.33 \\
A 5 & 0 & 0 & 0.08 & 0.08 & 0.08 & 0 & 0 & 0 & 0 & 0 & 0.08
\end{array}
$$

where values of each column give final weights of each element such as scenarios, criteria, and alternatives.

\subsection{Results}

As a result of the ANP analysis, the following priorities are given by $W^{*}$ :

- As for the alternative: A4 (0.33)> A1 (0.32) > A3 (0.21) > A2 (0.17) > A5 (0.08)

- As for the scenario: $\mathrm{S} 1(0.55)>\mathrm{S} 2(0.45)$

- As for the criterion: $\mathrm{C} 1(0.44)>\mathrm{C} 2(0.36)>\mathrm{C} 3(0.20)$

The results indicate that the activities for the new project should be "early fire detection and control" (A4), "political measures" (A1), "forest (including peat bog) management and conservation" (A3), "enlightenment and capacity building" (A2), and "burn assessment and afforestation" (A5) in order of high priority.

\section{Conclusion}

This paper highlighted an application of the AHP/ANP technique to the field of project management. It is shown that the AHP/ANP can provide a mathematical approach to decision-makings in project management. It is also found that the AHP/ANP is useful for analyzing the subject in a comprehensive, manifold, and interdisciplinary way through its process of structuring hierarchy.

In fact, a project for wildfire and carbon management in a peat-forest in Kalimantan, Indonesia, is going to be initiated. This interdisciplinary project primarily consists of "early fire detection and control" (A4) and "forest (including peat bog) management and conservation" (A3), and the Sentinel Asia wildfire management WG is due to participate. Note that "political measures such as a ban on slash-and-burnfarming" (A1) is a matter of policy, and unsuitable for a project activity. 


\section{REFERENCES}

Held, A., Dyce, P., Swan, G., Carmody, D., Moss, O., Woolner, J., and Shepherd, I. (2003). "Developing the Sentinel Hotspots Fire Location Website", Proceedings of 3rd International Wildland Fire Conference, Sydney, October, 2003.

Kaku, K., Held, A., Fukui, H., and Arakida, M. (2006). SENTINEL-ASIA INITIATIVE FOR DISASTER MANAGEMENT SUPPORT IN THE ASIA-PACIFIC REGION. Proceedings of SPIE, Vol. 6412

Kaku, K. and Fukuda, M. (2008a). Overview of Sentinel Asia's Approach to Wild Fire Detection Using Remote Sensing Technology, Asian Journal of GEOINFORMATICS, 8(3), 3-11

Kaku, K., Honma, T., and Fukuda, M. (2008b). AHP and ANP Evaluation of Wildfire Project Management using Remote Sensing Technology, presented in the 4th International Project Management Conference, Anchorage, September, 2008

Kaku, K., (2008c). Sentinel Asia - the next step, Risk Wise, 183-186: Tudor Rose

Kinoshita, E. (2000). An Introduction to AHP (in Japanese). Tokyo: Nikkagiren

Page, S., Seagert, F., Riely, J., Boehm, R., Jaya, A., and Limen, S. (2002). The amount of Carbon released from peat and forest fires in Indonesia during 1997, Nature Vol. 420, 61-65

Saaty, T.L. (1980). The Analytic Hierarchy Process. New York: McGraw-Hill 